\title{
Role of early luteal phase progesterone in control of the timing of the luteolytic signal in cows
}

\author{
G. E. Mann, G. E. Lamming and J. H. Payne \\ Department of Physiology and Environmental Science, University of Nottingham, Sutton Bonington, \\ Loughborough LE12 5RD, UK
}

\begin{abstract}
The effects of the pattern and concentration of early luteal phase progesterone on subsequent prostaglandin $\mathrm{F}_{2 a}$ release in response to exogenous oxytocin was investigated during simulated luteal phases in ovariectomized cows treated with progesterone and oestradiol in patterns designed to simulate the range of luteal phase concentrations that occur naturally. In the first experiment, three groups of four cows received different concentrations of early luteal phase progesterone to determine the effective concentration in terms of cycle control. The results show that a plasma progesterone concentration early in the luteal phase as low as $0.6 \mathrm{ng} \mathrm{ml}^{-1}$ was sufficient to affect the timing of the subsequent luteolytic signal. In the second experiment, an early (day 1), a normal (day 4) or a late (day 7) postovulatory increase in progesterone was recreated in three groups of four cows. Responsiveness to oxytocin in the early progesterone group developed 3 days earlier than in the normal progesterone group, demonstrating the ability of early progesterone to advance the luteolytic signal. However, in the late progesterone group, there was no delay in the development of responsiveness to oxytocin compared with the normal progesterone group, demonstrating that the luteolytic signal is programmed to occur by a given time, irrespective of the early progesterone pattern. This demonstrates that a factor other than the timing of the early luteal phase progesterone increase ultimately must control the timing of luteolysis in cows.
\end{abstract}

\section{Introduction}

In cattle and sheep, luteolysis occurs as a result of the release of luteolytic episodes of uterine prostaglandin $\mathrm{F}_{2 \alpha}\left(\mathrm{PGF}_{2 \alpha}\right)$ in response to the binding of oxytocin to newly developed endometrial oxytocin receptors (Wathes and Lamming, 1995). The role of progesterone in the control of this process is well documented (for reviews see Silvia et al., 1991; Geisert et al., 1992; Wathes and Lamming, 1995), with progesterone controlling both oxytocin receptor development and $\mathrm{PGF}_{2 \alpha}$ release (Lamming and Mann, 1995a). In cattle and sheep, administration of progesterone early in the luteal phase to advance the postovulatory progesterone increase shortens the oestrous cycle (Woody et al., 1967; Ottobre et al., 1980), demonstrating the ability of the early progesterone increase to control the timing of subsequent luteolysis. In contrast, delaying the increase in progesterone might be expected to delay luteolysis and increase the duration of the cycle. However, this theory has never been tested as it is impossible to delay the increase in progesterone in cyclic animals without affecting other aspects of the cycle. However, it is possible to delay the timing of the postovulatory increase when recreating hormone patterns in steroid hormone-treated ovariectomized cows. Treatment of ovariectomized cows with progesterone and oestradiol to recreate normal oestrous cycle concentrations

Revised manuscript received 12 December 1997. results in the development of an active population of endometrial oxytocin receptors and $\mathrm{PGF}_{2 u}$ release to exogenous oxytocin challenge, analogous to the luteolytic signal in intact animals (Lamming and Mann, 1995b).

This model has been used to determine both the effective early luteal phase concentration of progesterone and the importance of the time at which this concentration is achieved in the control of the timing of subsequent luteolysis.

\section{Materials and Methods}

\section{Animals}

Blue-Grey cows that had been ovariectomized several years previously were used. Animals were given a series of hormone treatments designed to recreate similar, although not identical, changes in plasma hormone concentrations to those seen in intact cyclic cows. Initially, cows received a steroid hormone pretreatment regimen comprising 14 days 'luteal phase' progesterone followed by 2 days 'follicular phase' oestradiol. The progesterone pretreatment was given via an intravaginal progesterone releasing device (CIDR-B, SmithKline Animal Health, Tadworth, Surrey). The oestradiol treatment was initiated on the morning of CIDR withdrawal and consisted of six i.m. injections of a solution of oestradiol (Sigma Chemical Co., Poole, Dorset) in corn oil (25, 50, 75, 100, 100 and $100 \mu \mathrm{g}$ 
Table 1. Total daily amounts of progesterone (mg) administered to ovariectomized cows given zero $(n=4)$ low $(n=4)$ or medium $(n=4)$ concentrations of progesterone during the early stages of the simulated luteal phase (Expt I)

\begin{tabular}{lrrr}
\hline Day & Zero & Low & Medium \\
\hline $1-2$ & 0 & 0 & 0 \\
$3-7$ & 0 & 20 & 40 \\
8 & 200 & 200 & 200 \\
$9-18$ & 300 & 300 & 300 \\
\hline
\end{tabular}

oestradiol, respectively) at $8 \mathrm{~h}$ intervals over $40 \mathrm{~h}$. This treatment regimen has been shown to produce a situation 3-4 days after the oestradiol treatment equivalent to the early luteal phase in intact cyclic animals, with low endometrial oxytocin receptor concentrations and no $\mathrm{PGF}_{2 \alpha}$ response to an oxytocin challenge (Lamming and Mann, 1995b). The timing of subsequent treatments was defined relative to the second day of oestradiol pretreatment (defined as day 0 ) on which all cows showed oestrus.

On day 0 , each cow received a single subcutaneous Silastic implant containing oestradiol (Lamming and Mann, 1995b), which was maintained throughout the experiments to generate luteal phase concentrations of oestradiol. Progesterone was administered by i.m. injection twice a day of appropriate volumes of a solution of progesterone in corn oil $\left(20 \mathrm{mg} \mathrm{ml}^{-1}\right)$.

\section{Experimental design}

Experiment 1. Cows were treated with either $0 \mathrm{mg}$ progesterone day ${ }^{-1}$ (zero; $n=4$ ), $20 \mathrm{mg}$ progesterone day ${ }^{-1}$ (low; $n=4$ ) or $40 \mathrm{mg}$ progesterone day ${ }^{-1}$ (medium; $n=4$ ) from day 3 to day 7 of a simulated luteal phase to determine the effect of different concentrations of early luteal phase progesterone in controlling the timing of development of the luteolytic signal. All cows then received a standard pattern of progesterone from day 8 to day 18 according to the protocol shown (Table 1). Blood samples for progesterone determination were collected each day from day 0 to day 7 and every 3 days from day 9 to day 18. All samples were collected $6 \mathrm{~h}$ after the morning injection of progesterone. Responsiveness to oxytocin was monitored on days 12, 15 and 18 of the simulated luteal phase to determine the effect of each concentration of progesterone in triggering the subsequent development of a luteolytic signal.

Experiment 2. Cows were treated with progesterone for 15 days starting early (days $1-15 ; n=4$ ) normal (days 4-18; $n=4$ ) or late (days $7-21 ; n=4$ ) during simulated luteal phases according to the protocol shown (Table 2) to determine the importance of the timing of the postovulatory progesterone rise on the subsequent timing of the luteolytic signal. Blood samples for progesterone determination were collected at 2 day intervals before initiation of progesterone treatment, each day from day 1 to day 6 of progesterone treatment and then every 3 days from day 9 to day 15 of progesterone treatment. All
Table 2. Total daily amounts of progesterone (mg) administered to cows in which were recreated early $(n=4)$, normal $(n=4)$ and late $(n=4)$ increases in progesterone (Expt 2)

\begin{tabular}{rlll}
\hline Day & Early & Normal & Late \\
\hline 1 & 30 & 0 & 0 \\
2 & 60 & 0 & 0 \\
3 & 120 & 0 & 0 \\
4 & 180 & 30 & 0 \\
5 & 240 & 60 & 0 \\
6 & 300 & 120 & 0 \\
7 & 300 & 180 & 30 \\
8 & 300 & 240 & 60 \\
9 & $300^{*}$ & 300 & 120 \\
10 & 300 & 300 & 180 \\
11 & 300 & 300 & 240 \\
12 & $300^{*}$ & $300^{*}$ & 300 \\
13 & 300 & 300 & 300 \\
14 & 300 & 300 & 300 \\
15 & $300^{*}$ & $300^{*}$ & $300^{*}$ \\
16 & - & 300 & 300 \\
17 & - & 300 & 300 \\
18 & - & $300^{*}$ & $300^{*}$ \\
19 & - & - & 300 \\
20 & - & - & 300 \\
21 & - & - & $300^{*}$ \\
& - & & \\
\hline & - & &
\end{tabular}

*Days on which responsiveness to oxytocin was determined by oxytocin challenge.

samples were collected $6 \mathrm{~h}$ after the morning injection of progesterone. In all cows, irrespective of the day on which progesterone treatment was initiated, responsiveness to oxytocin was monitored on days 9, 12 and 15 of progesterone treatment (that is, on days 9,12 and 15 after induced oestrus in the early group; days 12, 15 and 18 after induced oestrus in the normal group; and days 15, 18 and 21 after induced oestrus in the late group).

\section{Blood sampling and oxytocin challenges}

Before the start of oestradiol pretreatment, a jugular vein of each animal was cannulated under local anaesthesia $(2 \mathrm{ml}$ lignocaine s.c. as Lignovet $2 \%(w / v)$, C-Vet, Bury St Edmunds) with a $30 \mathrm{~cm}$ indwelling jugular catheter (Secalon universal tubing, BOC Health Care, Swindon) using a 12 gauge needle and $80 \mathrm{~cm}$ guide wire. Cannulae were then maintained for the duration of the experiment and used for the collection of all blood samples. Cows were injected with a single i.v. bolus of 50 iu oxytocin (Hoechst UK Ltd, Milton Keynes) in $5 \mathrm{ml}$ saline, flushed in with a further $5 \mathrm{ml}$ saline to monitor endometrial responsiveness to oxytocin. Plasma concentrations of 13,14dihydro-15-keto PGF $_{2 u}$ (PGFM), the principal metabolite of $\mathrm{PGF}_{2 \alpha^{\prime}}$ were measured in blood samples collected at $20 \mathrm{~min}$ intervals for $1 \mathrm{~h}$ before the injection of oxytocin and then at $10 \mathrm{~min}$ intervals for the first $1 \mathrm{~h}$ after the challenge and at $20 \mathrm{~min}$ intervals for a further $1 \mathrm{~h}$. All samples were collected into heparinized tubes, centrifuged at $1500 \mathrm{~g}$ for $10 \mathrm{~min}$ and the plasma stored at $-20^{\circ} \mathrm{C}$. 
Assays

Plasma samples were assayed for PGFM after extraction with acidified diethyl ether by radioimmunoassay (Kaker et al., 1984), using antibody supplied by $\mathrm{H}$. Dobson, University of Liverpool. Crossreactivities were $8 \%$ with $15-$ keto $\mathrm{PGF}_{2 a^{\prime}}, 0.7 \%$ with 13,14-dihydro $\mathrm{PGF}_{2 \alpha^{\prime}} 0.5 \%$ with $\mathrm{PGF}_{1 u^{\prime}} \mathrm{PGE}_{1}$ and $\mathrm{PGE}_{2}$ and $0.1 \%$ with $\mathrm{PGF}_{2 \alpha}$. The sensitivity of the assay was $15 \mathrm{pg}$ $\mathrm{ml}^{-1}$, and the intra- and interassay coefficients of variation were $<15$ and $13.6 \%$, respectively. Progesterone was measured in plasma samples after extraction with petroleum ether by radioimmunoassay (Haresign et al., 1975) with antisera obtained from B. J. A. Furr. Crossreactivities were $0.6 \%$ with $17 \alpha$ hydroxyprogesterone, $1.1 \%$ with $20 \alpha$ dihydroprogesterone, $4.3 \%$ with cortisol, $4.2 \%$ with corticosterone, $2.6 \%$ and $<0.5 \%$ with oestradiol, oestrone, testosterone, $5 \alpha$-dihydrotestosterone and oestriol. The sensitivity of the assay was $0.2 \mathrm{ng} \mathrm{mi}^{-1}$, and the intra- and interassay coefficients of variation were $<10 \%$ and $11.3 \%$, respectively. Oestradiol was measured in plasma using a modified radioimmunoassay kit (Serono Diagnostics Ltd, Woking) (Mann et al., 1995). Crossreactivities were $1.8 \%$ with oestrone, $0.5 \%$ with oestriol and $<0.01 \%$ with progesterone, testosterone, androstenedione and dihydrotestosterone. The sensitivity of the assay was $0.5 \mathrm{pg} \mathrm{ml}^{-1}$, and the intra- and interassay coefficients of variation were $<1.0 \%$ and $9.6 \%$, respectively.

\section{Statistical analysis}

Differences in plasma concentrations of progesterone were analysed by repeated sample analysis of variance. Significant responses to oxytocin were defined as having occurred when the concentration of PGFM at three consecutive time points after the bolus challenge was greater than the pretreatment mean $+2 \mathrm{SD}$ and were defined as having ended when the concentration in a single sample fell below this concentration. Differences in the magnitude of responses to oxytocin were analysed by analysis of variance.

\section{Results}

\section{Experiment 1}

Mean \pm SEM plasma concentrations of progesterone generated by the three treatments during the early part of the simulated luteal phase were significantly different $(P<0.001$; Fig. Ia). In the zero group, plasma progesterone concentrations from day 4 to day 7 remained below the sensitivity of the assay $\left(<0.2 \mathrm{ng} \mathrm{ml}^{-1}\right)$, while in the low and medium groups, plasma concentrations of progesterone increased to $0.6 \pm 0.1 \mathrm{ng} \mathrm{ml}^{-1}$ and $1.2 \pm 0.1 \mathrm{ng} \mathrm{ml}^{-1}$, respectively. Plasma concentrations of progesterone then increased markedly in all groups up to day 12 , when concentrations remained steady until day 18 (Fig. 1b). Mean \pm SEM plasma concentrations of oestradiol during the simulated luteal phases were similar in all groups ( $1.6 \pm 0.2 \mathrm{pg} \mathrm{ml}^{-1}$ ).

The mean \pm SEM increase in plasma PGFM in response to oxytocin (expressed as a percentage of pretreatment baseline) and the proportion of cows exhibiting significant responses are

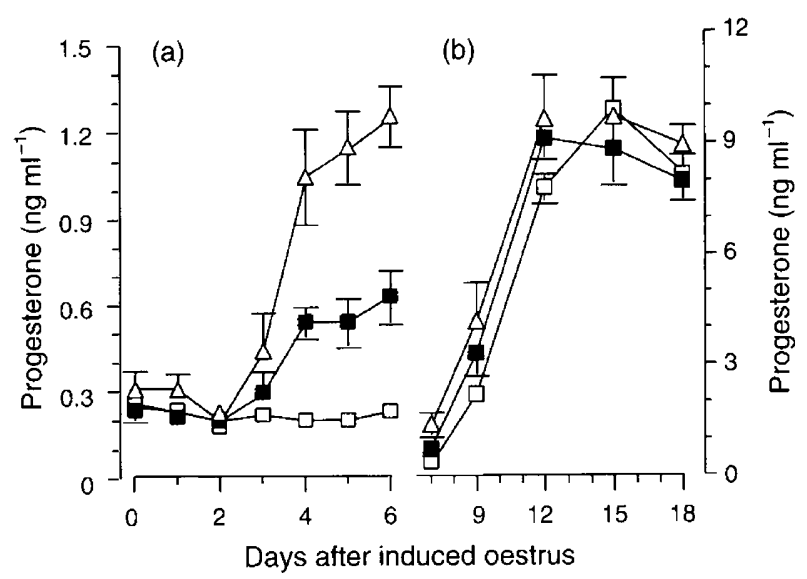

Fig. 1. Mean \pm SEM plasma concentration of progesterone generated (a) from day 0 to day 6 and (b) from day 7 to day 18 (note differing $y$ axes) after induced oestrus, in ovariectomized cows treated with zero $(\square ; n=4)$, low $(\boldsymbol{\square} ; n=4)$ or medium $(\triangle ; n=4)$ progesterone from day 3 to day 7 and a standard amount of progesterone from days 8 to day 18 after induced oestrus.

shown (Table 3). In the zero group, in which no progesterone was administered until day 8 of the simulated cycle, none of the cows showed a significant response to oxytocin until day 18 , when all four cows responded to oxytocin. In contrast, in the low and medium groups $3 / 4$ cows and $4 / 4$ cows, respectively, responded to oxytocin on days 12 and 15 . Mean response to oxytocin was significantly $(P<0.05)$ greater in the low and medium groups than in the zero group on these 2 days. On day 18, all cows in all groups responded to oxytocin, with the response in the medium group being significantly $(P<0.05)$ greater than in the zero group.

\section{Experiment 2}

The three different progesterone treatment regimens produced similar patterns of progesterone but at significantly $(P<0.001)$ different times. The increase in the early group occurred 3 days earlier than that in the normal group and the increase in the late group, 3 days later (Fig. 2). However, the plateau concentrations of progesterone achieved in the three groups over the periods of the oxytocin challenges (early days $9-15,9.1 \pm 0.8 \mathrm{ng} \mathrm{ml}^{-1}$; normal days $12-18,9.2 \pm 0.5 \mathrm{ng}$ $\mathrm{ml}^{-1}$; late days $15-21,8.7 \pm 0.7 \mathrm{ng} \mathrm{ml}^{-1}$ ) were similar. The mean \pm SEM plasma concentration of oestradiol generated during the simulated luteal phases was similar in the three groups $\left(1.8 \pm 0.3 \mathrm{pg} \mathrm{ml}^{-1}\right.$ ).

The mean \pm SEM increase in plasma PGFM in response to oxytocin (expressed as a percentage of pretreatment baseline) is shown (Table 4). In all groups, irrespective of the time at which progesterone treatment was started, there was a consistent significant $(P<0.05)$ increase in responsiveness to oxytocin with time, demonstrating the temporal development of a luteolytic signal. In the early group, there was a similar pattern of development of oxytocin responsiveness to that seen in the normal group, but this pattern developed 3 days earlier than in the normal group. In the early group, day 9,12 and 15 chailenges gave similar responses to the normal group day 12 , 
Table 3. Mean \pm SEM increase in plasma 13,14-dihydro-15-keto $\mathrm{PGF}_{2 u}$ (PGFM) (as a percentage of pretreatment baseline) during the $2 \mathrm{~h}$ after oxytocin challenges (50 iu) on days 12,15 and 18 after induced oestrus in ovariectomized cows treated from day 3 to day 7 with zero $(n=4)$, low $(n=4)$ or medium $(n=4)$ progesterone and from day 8 to day 18 with a standard amount of progesterone

\begin{tabular}{lccc}
\hline & \multicolumn{3}{c}{ Day after induced oestrus } \\
\cline { 2 - 4 } $\begin{array}{l}\text { Concentration of } \\
\text { early progesterone }\end{array}$ & Day 12 & Day 15 & Day 18 \\
\hline $\begin{array}{lcc}\text { Zero } \\
(n=4)\end{array}$ & $8.1 \pm 6.6^{\mathrm{a}}$ & $\begin{array}{c}11.8 \pm 2.9^{\mathrm{a}} \\
(0 / 4)\end{array}$ & $\begin{array}{c}71.9 \pm 10.8^{\mathrm{b}} \\
(4 / 4)\end{array}$ \\
Low & $(0 / 4)$ & $99.4 \pm 32.6^{\mathrm{bc}}$ & $(3 / 4)$ \\
$(n=4)$ & $56.0 \pm 20.8^{\mathrm{bc}}$ & $(3 / 4)$ & $118.6 \pm 27.6^{\mathrm{bc}}$ \\
Medium & $92.4 \pm 18.5^{\mathrm{bc}}$ & $(4 / 4)$ & $(4 / 4)$ \\
$(n=4)$ & $(4 / 4)$ & $(4 / 4)$ & $166.7 \pm 26.3^{\mathrm{bc}}$ \\
\hline
\end{tabular}

Values in parentheses represent proportion of cows showing a significant response to oxytocin challenge.

Values with different superscript letters differ significantly $(P<0.05$; analysis of variance).

Table 4. Mean \pm SEM increase in plasma 13,14-dihydro-15-keto PGF 2 (PGFM) (as a percentage of pretreatment baseline) during the $2 \mathrm{~h}$ after oxytocin challenges (50 iu) to ovariectomized cows treated with a standard 15 day progesterone treatment regimen beginning either early (day $1 ; n=4$ ), normal (day $4 ; n=4$ ) or late (day $7 ; n=4$ ) after induced oestrus

\begin{tabular}{lccccc}
\hline \multirow{2}{*}{$\begin{array}{l}\text { Progesterone } \\
\text { increase }\end{array}$} & Day 9 & Day 12 & Day 15 & Day 18 & Day 21 \\
\cline { 2 - 6 } & $\begin{array}{l}14.3 \pm 4.3^{\mathrm{a}} \\
\text { Early }\end{array}$ & $\begin{array}{c}30.8 \pm 3.7^{\mathrm{b}} \\
(\text { day } 12)\end{array}$ & $\begin{array}{c}70.5 \pm 12.2^{\text {cd }} \\
(\text { day } 15)\end{array}$ & - & - \\
Normal & - & $\begin{array}{c}19.0 \pm 2.7^{\mathrm{a}} \\
(\text { day } 9)\end{array}$ & $\begin{array}{c}36.8 \pm 5.2^{\mathrm{b}} \\
(\text { day } 12)\end{array}$ & $\begin{array}{c}67.0 \pm 7.5^{\mathrm{c}} \\
(\text { day } 15)\end{array}$ & - \\
Late & - & - & $\begin{array}{c}31.7 \pm 5.3^{\mathrm{b}} \\
(\text { day } 9)\end{array}$ & $\begin{array}{c}65.4 \pm 6.8^{\mathrm{c}} \\
(\text { day } 12)\end{array}$ & $\begin{array}{c}99.4 \pm 3.6^{\mathrm{d}} \\
(\text { day } 15)\end{array}$ \\
\hline
\end{tabular}

Values in parentheses represent the actual day of progesterone treatment on which each oxytocin challenge was performed.

Values with different superscript letters differ significantly $(P<0.05$; analysis of variance).

15 and 18 challenges, respectively. Thus, on a given day, the response to oxytocin in the early group was significantly $(P<0.05)$ larger than the response in the normal group on that day, and was in fact similar in magnitude to the response seen in the normal group 3 days later, indicating that the early progesterone had led to the early development of the luteolytic signal. However, in the late group, the response to oxytocin on a given day was similar to that seen on the same day in the normal group and was significantly $(P<0.05)$ larger than the response seen 3 days earlier in the normal group. Thus, oxytocin responsiveness in the late group had developed on the same day of the simulated cycle as in the normal group, despite the delay in the timing of the increase in progesterone.

\section{Discussion}

The results of this study in ovariectomized cows support the well established observation that advancing the timing of the postovulatory increase in progesterone results in an equivalent advancement of the timing of the luteolytic signal (Woody et al., 1967; Ottobre et al., 1980; Garrett et al., 1988). However,

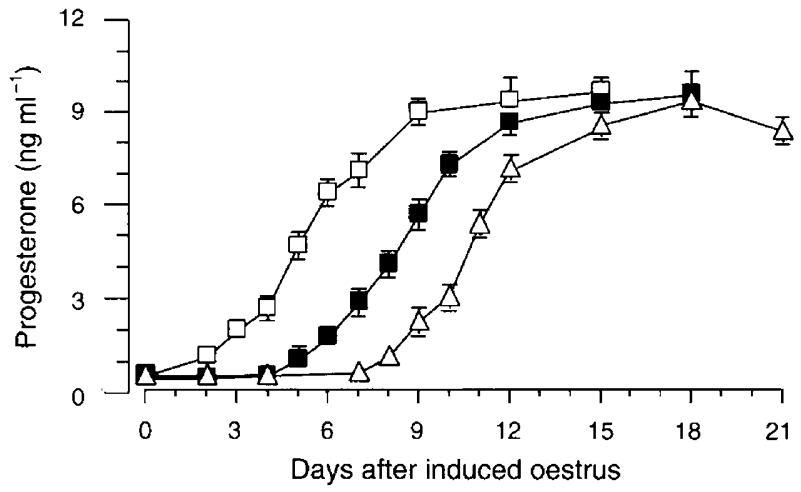

Fig. 2. Mean \pm SEM plasma concentration of progesterone generated in ovariectomized cows treated with a standard 14 day pattern of progesterone replacement starting on day $I$ (early; $\square ; n=4$ ), day 4 (normal; $\mathbf{\square} ; n=4$ ) or day 7 (late; $\Delta ; n=4$ ) after induced oestrus.

contrary to expectations, when the postovulatory increase in progesterone was delayed, this did not delay the development of the luteolytic signal. This means that the timing of the 
postovulatory progesterone increase does not ultimately control the timing of luteolysis as originally postulated. The observation that early progesterone advances luteolysis does show that progesterone can influence the process, but the occurrence of luteolytic signal at the 'normal' time in the presence of a delayed progesterone increase demonstrates that the factor ultimately responsible for controlling cycle duration can act independently of progesterone control.

While it is well established in cows that administration of early progesterone can influence the subsequent timing of luteolysis, the 'effective' concentration of progesterone at this time is not known. In this study, a plasma concentration of progesterone of as low as $0.6 \mathrm{ng} \mathrm{ml}^{-1}$ was found to be sufficient to trigger a premature luteolytic signal in most cows. This indicates that the point at which progesterone becomes effective is shortly after the onset of the postovulatory increase. On the basis of this observation, it can be seen from the results of Expt 2 that a period of exposure to an effective concentration of progesterone for 10 days is sufficient to elicit a moderate response to oxytocin in the early and normal groups, while in the late group, an equivalent response was seen after exposure to an effective concentration of progesterone for only 7 days. Large responses to oxytocin were seen after 13 days of progesterone exposure in the early and normal groups and after 10 days in the late group.

The role of progesterone during the luteal phase is to inhibit the development of the endometrial oxytocin receptor until the appropriate time, while at the same time inducing endometrial ability to synthesis and release $\mathrm{PGF}_{2 \alpha}$ in response to oxytocin (Lamming and Mann, 1995a). Exposure to progesterone for only 6 days is sufficient to induce maximal ability to release $\mathrm{PGF}_{2 \alpha}$ in response to oxytocin (Lamming and Mann, 1995a), so it would seem more likely that the influence of progesterone on the timing of luteolysis is mediated through the control of the oxytocin receptor. The results of the current study support the theory that premature exposure to progesterone advances the time at which the ability of progesterone to inhibit the appearance of endometrial oxytocin receptors is lost. However, the fact that in the late progesterone group, responsiveness to oxytocin began to develop after only 7 days of progesterone exposure, disproves the suggestion that the total period of progesterone exposure is the ultimate controller of cycle duration. It appears that some factor other than progesterone programs the timing of the loss of progesterone inhibition of oxytocin receptor development, irrespective of the progesterone environment experienced by the cow. Early progesterone can advance this loss, but the preprogramming overrides any effect of a late progesterone increase. One possibility is that an oxytocin receptor inhibitor may be produced during the luteal phase (Wathes and Lamming, 1995). The timing of the production of such an inhibitor could be advanced by early exposure to progesterone but not delayed by late exposure to progesterone.

During the early stages of pregnancy, progesterone, as well as controlling the development of the luteolytic mechanism, stimulates the production of the endometrial secretions necessary for embryo development (Geisert et al., 1992). In cattle and sheep, increased concentrations of progesterone early in the luteal phase are associated with enhanced embryonic production of the antiluteolytic signal, interferon $\tau$ (Kerbler et al.
1997. Nephew et al., 1991). Thus, a delayed postovulatory progesterone increase would probably result in poor embryo development and reduced interferon $\tau$ production. As a delay in the postovulatory progesterone increase would not cause a delay in the timing of luteolysis, it is likely that in a mated animal, such a delay would result in the failure of the embryo to inhibit luteolysis. A late postovulatory increase in progesterone results in poor embryo development and failed inhibition of luteolytic PGF $_{2 \alpha}$ release (Mann et al., 1996). Furthermore, it has been shown, in dairy cows, that a delayed postovulatory increase in progesterone is associated with a shorter subsequent period of luteal phase progesterone secretion and a poor pregnancy rate after mating (Lamming and Darwash, 1995).

The authors thank S. Machin for technical assistance. The work was supported by a grant from the Milk Marketing Board of England and Wales. The oxytocin was donated by Hoechst, the CIDR-B devices by SmithKline Animal Health and the PGFM antiserum was a gift from H. Dobson.

\section{References}

Garrett JE, Geisert RD, Zavy MT, Gries LK, Wettemann RP and Buchanan DS (1988) Effect of exogenous progesterone on prostaglandin $F_{2 \mu}$ release and the interestrous interval in the bovine Prostaglandins 36 85-96

Geisert RD, Morgan GL, Short EC and Zavy MT (1992) Endocrine events associated with endometrial function and conceptus development in cattle Reproduction Fertility and Development 4 301-305

Haresign W, Foster JP, Haynes NB, Crighton DB and Lamming GE (1975) Progesterone levels following treatment of seasonally anoestrous ewes with synthetic LH-releasing hormone Journal of Reproduction and Fertility $\mathbf{4 3}$ 269-279

Kaker ML, Murray RD and Dobson H (1984) Plasma hormone changes in cows during induced or spontaneous calvings and the early post partum period Veterinary Record 115 378-382

Kerbler TL, Buhr MM, Jordan LT, Leslie KE and Walton JS (1997) Relationship between maternal plasma progesterone concentration and interferon-tau synthesis by the conceptus in cattle Theriogenology 47 703-714

Lamming GE and Darwash AO (1995) Effect of inter-luteal interval on subsequent luteal phase length and fertility in post partum dairy cows Biology of Reproduction 52 (Supplement 1) Abstract 72

Lamming GE and Mann GE (1995a) A dual role for progesterone in the control of cyclicity in domestic ruminants Journal of Reproduction and Fertility Supplement $49561-566$

Lamming GE and Mann GE (1995b) Control of endometrial oxytocin receptors and prostaglandin $\mathrm{F}_{2 u}$ production in the cow by progesterone and oestradiol Journal of Reproduction and Fertility 103 69-73

Mann GE, Lamming GE and Fray MD (1995) Plasma oestradiol during early pregnancy in the cow and the effects of treatment with buserelin Animal Reproduction Science 37 121-131

Mann GE, Mann SI and Lamming GE (1996) The inter-relationship between the maternal hormone environment and the embryo during the early stages of pregnancy Journal of Reproduction and Fertility Abstract Series 17 Abstract 55

Nephew KP, McClure KE, Ott T, Budois DH, Bazer FW and Pope WF (1991) Relationship between variation in conceptus development and differences in estrous cycle duration in ewes Biology of Reproduction 44 536-539

Ottobre JS, Lewis GS, Thayne WZ and Inskeep EK (1980) Mechanism by which progesterone shortens the estrous cycle of the ewe Biology of Reproduction 23 1046-1053

Silvia WJ, Lewis GS, McCracken JA, Thatcher WW and Wilson L (1991) Hormonal regulation of uterine secretion of prostaglandin $F_{2 a}$ during luteolysis in ruminants Biology of Reproduction 45 655-663

Wathes DC and Lamming GE (1995) The oxytocin receptor, luteolysis and the maintenance of pregnancy Journal of Reproduction and Fertility Supplement 49 $53-67$

Woody CD, First NL and Pope AL (1967) Effect of exogenous progesterone on estrous cycle length Journal of Animal Science 26 139-141 